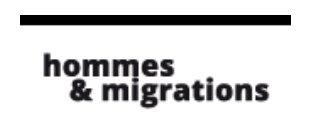

\section{Hommes \& migrations}

Revue française de référence sur les dynamiques

migratoires

France - Algérie, le temps du renouveau

\title{
Hélène Erlingsen-Creste, Mohamed Zerouki, Nos pères ennemis, Morts pour la France et l'Algérie.
} 1958-1959

Toulouse, Privat, 2012, 175 pages, 16,50 euros

\section{Mustapha Harzoune}

\section{(2) OpenEdition}

\section{Journals}

Édition électronique

URL : http://journals.openedition.org/hommesmigrations/1601

DOI : 10.4000/hommesmigrations. 1601

ISSN : 2262-3353

Éditeur

Musée national de l'histoire de l'immigration

Édition imprimée

Date de publication : 1 juillet 2012

Pagination : 164-165

ISSN : 1142-852X

Référence électronique

Mustapha Harzoune, « Hélène Erlingsen-Creste, Mohamed Zerouki, Nos pères ennemis, Morts pour la France et l'Algérie. 1958-1959», Hommes \& migrations [En ligne], 1298 | 2012, mis en ligne le 29 mai 2013, consulté le 22 septembre 2020. URL : http://journals.openedition.org/hommesmigrations/1601 ; DOI : https://doi.org/10.4000/hommesmigrations.1601

Ce document a été généré automatiquement le 22 septembre 2020.

Tous droits réservés 


\section{Hélène Erlingsen-Creste, Mohamed Zerouki, Nos pères ennemis, Morts pour la France et l'Algérie. 1958-1959}

Toulouse, Privat, 2012, 175 pages, 16,50 euros

\section{Mustapha Harzoune}

\section{RÉFÉRENCE}

Hélène Erlingsen-Creste, Mohamed Zerouki, Nos pères ennemis, Morts pour la France et l'Algérie. 1958-1959, Toulouse, Privat, 2012, 175 pages, 16,50 euros

1 Se parler simplement. Se parler en respectant l'autre et sa douleur. La guerre d'Algérie a emporté les pères, les "pères ennemis" d'Hélène et de Mohamed. Chacun a vécu, et vit encore aujourd'hui, cette absence comme un grand blanc, un grand vide. "On est toujours en manque. Et même si la vie continue, une présence essentielle vous fait défaut. On devient des boiteux. On marche, on bouge, mais on claudique dans son cœur", dit Hélène. Elle a cherché à reconstituer la mémoire des faits et l'intimité des pensées. Les derniers instants de la vie de son père. Pour cela, elle a soutenu une thèse sur "La Politique coloniale de la IV République", écrit un livre intitulé Soldats perdus (Bayard, 2007) et parcouru le monde pour retrouver "les frères de sang", les "frères d'armes" et les "ennemis aussi" de son père. "J'ai pleuré, j'ai pleuré. Je crois que ma vie a été faite de ça. J'ai 66 ans et il y a des moments, quand il apparaît dans mes rêves, je me lève. Je me lève et je pleure", dit Mohamed, qui, un temps, accompagna son père dans les maquis. Il continue, aujourd'hui encore, de rechercher la dépouille de son père. Clovis et Ibrahim ne sont donc pas que des souvenirs. Ils sont là, bien présents dans le cœur et dans es pensées de cette fille et de ce fils, quelque cinq décennies après leur mort. En Algérie, comme en France, "l'émotion est encore trop grande", dit Mohamed. Se parler n'a pas été chose facile. Le temps a sans doute fait son œuvre mais aussi une capacité, une intelligence à aller au-delà de soi, vers l'autre. Non pour se réconcilier. Mais pour se reconnaître. "Nos 
convictions sont si proches qu'elles se fondent." Pour ouvrir la voie, écrire une nouvelle page "pour mes enfants", dit Hélène, et "mettre un petit caillou blanc sur le chemin de la réconciliation de nos deux pays". Hélène et Mohamed reconstituent les biographies paternelles. L'enfance et la jeunesse. La résistance pour l'un, l'injustice coloniale pour l'autre. L'engagement. Quand, en 1954, éclate la guerre de libération, Hélène fait défiler le fil des événements. Elle dénonce vigoureusement les responsabilités, les inconséquences, les fautes des politiques (les déclarations de François Mitterrand (pp. 33, 48-49, 65, 103,) de Bourges-Maunoury et du général Koenig (pp. 52, 66) ou de Christian Pineau (p. 79), l'immobilisme des 21 gouvernements qui se sont succédé de la libération à 1958, "la politique de l'Autruche" et le "mépris" affiché par Paris, la " disparition" de l'État de droit en Algérie, l'usage de méthodes qui rappellent celle de la Gestapo (p. 66), le cycle des violences, "cette surenchère de force armée sans la moindre mesure pour améliorer le sort des musulmans ne pouvait qu'aboutir à l'augmentation de la violence". Cette dénonciation n'est pas qu'intellectuelle. Elle se fait au nom des souffrances endurées par un homme, son père, et, à travers lui, au nom de ces soldats qui ont combattu pour la France, ceux qui sont morts pour la France mais aussi pour les survivants qui ne sont pas sortis indemnes de cette guerre. Il y eut la guerre militaire, celle des armes. Il y eut aussi les guerres intimes, celles des doutes indicibles. Il faut bien que les politiques rendent des comptes, de temps à autre: "Pendant huit ans, la France, mon pays, a sacrifié et fait sacrifier des milliers de vies d'hommes et de femmes, quels que soient leur camp et la couleur de leur peau, sur l'autel du prestige colonial." "J'en ai marre de cette sale vie", écrit Clovis à son épouse un soir de Noël 1956. Ou encore sur son agenda, il note, le 26 mai 1957 : "Journée de grand cafard. Vive la quille!" Il attend 1959 pour quitter l'armée, "après quinze ans de bons et loyaux services", et enfin réaliser son “ rêve", s'installer avec son épouse dans une petite ferme du Lot-et-Garonne. "On a fait battre des petits pauvres contre des petits pauvres", confiera le général Giap à Hélène. Mohamed, lui, rappelle les élections truquées et dévoile au lecteur la dure condition des maquisards algériens. Cela rappelle les reportages ou les écrits sur les maquis dans la France occupée. Il fait la différence entre "l'honneur et le respect" des maquisards et les surenchères des combattants de la 25e heure. Le "rêve" chez les Zerrouki, ce sont "plein de belles choses" à venir avec l'indépendance, chanter à l'unisson du père, main dans la main, dans les rues en fête d'Alger... Clovis et Ibrahim se sont peut-être croisés - ils opéraient dans la même zone -, "peut-être que les gens de ma famille ont tué son père", dit Mohamed. Dans le quotidien reconstitué de leurs pères, Hélène et Mohamed rappellent les valeurs que tous deux ont reçu en héritage : "le racisme, le mépris, tout ça, je n'ai pas connu. Mes parents m'ont toujours inculqué le respect, le partage et l'amour" (Hélène). "Ses valeurs n'étaient pas matérielles mais celles du cœur." "Il ne s'est pas battu contre les Français, mais contre le colonialisme." "On n'a pas de haine, dit Mohamed, on voulait foutre à la porte le racisme, mais pas les honnêtes gens." Cela, Hélène le vérifiera en 1992, lors de son séjour en Algérie, partie sur les traces de son père. Deux citations parmi celles placées en ouverture de chaque chapitre: "Eh! Qu'importe qui se trompe ou de vous ou de moi, pourvu que la paix soit entre nous?" (Diderot) et comme en écho, ces vers de Mohammed Dib : “ Pourquoi la vie vient-elle battre de ses vagues contre nos cours, sans les pénétrer? / (...) Parce qu'on ne peut pas ne pas espérer. "Le soldat Clovis Creste est mort en 1958, le moudjahid Ibrahim Zerouki a disparu en 1959. Le temps de la paix et de l'espoir est arrivé. 